\title{
Un dispositivo pedagógico desde la ruralidad para el desarrollo de competencias básicas
}

\section{A pedagogical device from rurality for the development of basic competences}

\begin{abstract}
Fecha de recepción: 20 de junio de 2017
Fecha de aprobación: 2 de septiembre de 2017

Artículo de reflexión

\section{Resumen}

En este artículo se exponen los resultados de una estrategia encaminada al desarrollo de competencias básicas, empleando aspectos novedosos que involucran los saberes escolares propios del contexto rural. Se establecieron relaciones de saberes y poderes tanto de los docentes como de los estudiantes, que permitieron una mejor comunicación y aprendizajes significativos mutuos, aportaron
\end{abstract}

\author{
Yennifer Maritza Chinchilla Villate* \\ Carlos Alberto Mongui Naranjo **: \\ Andrés Fernando Sarabanda Barrera $* * *$ \\ Ana Mercedes Pérez Martínez $* * * * *$
}

elementos valiosos que contribuyeron al logro del objetivo. El artículo expone la creación e implementación de un dispositivo pedagógico dirigido a los estudiantes de grado octavo de la Institución Educativa Marco Antonio Quijano Rico del sector rural del Municipio de Sogamoso; mediante la metodología "investigación - acción" se unificaron procesos aparentemente independientes que permitieron la
*Institución Educativa Integrada Marco Antonio Quijano Rico

yenimachi82@yahoo.es

**Institución Educativa Integrada Marco Antonio Quijano Rico carlosmongui@gmail.com ***Institución Educativa Integrada Marco Antonio Quijano Rico

fernandosarabanda@ hotmail.com

****Universidad Pedagógica y Tecnológica de Colombia mercedes.perez@uptc.edu.co

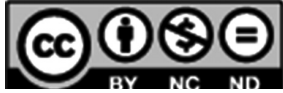


reflexión y superación de problemáticas propias del aula en contextos particulares y significativos para los estudiantes, estrategia que puede ser aplicada en contextos semejantes.

\section{Abstract}

This article presents the results of a strategy aimed at the development of basic skills, using trending aspects that involve school knowledge typical of the rural context. Relationships of knowledge and powers of both teachers and students were established, which allowed better communication and mutual meaningful learning, giving valuable elements that contributed to the achievement of the objective. The article exposes the creation and implementation of a pedagogical device directed to the eighth grade students of the "Marco Antonio Quijano Rico"
Palabras clave: dispositivo pedagógico, competencia, educación, ruralidad, contexto.

Educational Institution of the rural sector of the Municipality of Sogamoso; Through the "research - action" methodology, apparently independent processes were unified which allowed the reflection and overcoming of problems inherent to the classroom in particular and significant contexts for students, a strategy that can be applied in similar contexts.

Keywords: pedagogical device, competence, education, rurality, context. 


\section{Introducción}

Debido a los cambios tecnológicos, sociales y económicos acelerados del país, el sector rural se ha visto abocado a grandes transformaciones, entre ellas su educación; en este marco, la educación rural ha sido objeto de diferentes interpretaciones conceptuales y sometida a estándares de calidad, muchas veces ajenos a su contexto en función de la política educativa vigente tanto en Latinoamérica como en Colombia.

Las pruebas externas "saber" con las que se mide la adquisición de competencias de los estudiantes y avances de las instituciones educativas, pretenden estandarizar los conocimientos de los educandos, olvidando el contexto en que se encuentran los pobladores, el nivel socioeconómico y cultural en el que se desenvuelven. A primera vista, el método de homogeneizar los aprendizajes que buscan el desarrollo de competencias, parece favorecer el principio de igualdad, pero este mecanismo fomenta la discriminación en el sentido de medir con el mismo instrumento las capacidades y saberes de los escolares ubicados en diferentes contextos educativos y socioculturales; fomentando en los jóvenes la idea de que la educación que reciben es ajena a su contexto y, muchas veces, alejada de su comprensión y carente de sentido, lo que provoca el desplazamiento a la zona urbana y el abandono del campo.

En este sentido, el colectivo investigador propuso como estrategia un dispositivo pedagógico, con el objetivo de Establecer la influencia de las realidades de contexto en el desarrollo de las competencias generales básicas de los estudiantes de grado octavo de la Institución Educativa Integrada Marco Antonio Quijano Rico del Municipio de Sogamoso, que articule la formación académica impartida en la institución educativa con los saberes ancestrales desde la práctica del cultivo de la papa donde se involucran a padres de familia y estudiantes, con el ánimo de rescatar y potencializar los lenguajes y tradiciones culturales de los campesinos desde la agricultura; dicho dispositivo articula la historia, cultivo y productos obtenidos de la papa. Mediante el cúmulo de relaciones que se tejen con los conocimientos académicos de los docentes, dicho dispositivo se convierte en un conector idóneo para el mejoramiento de competencias básicas en las diferentes áreas del conocimiento escolar. El resultado de esta investigación se presenta en este artículo donde se muestra la problemática a solucionar, los desarrollos y resultados de la aplicación de la estrategia, además, las conclusiones y recomendaciones obtenidas de esta investigación.

\section{Referentes teóricos}

\section{Dispositivo pedagógico}

El término "Dispositivo" se empezó a usar en diferentes áreas del conocimiento en la segunda mitad del siglo XX. Su origen etimológico viene del latín "dispositus" que traduce "dispuesto", esto es, un conjunto de elementos heterogéneos que pueden ser diversos, pero que, articulados de
Las pruebas externas "saber" con las que se mide la adquisición de competencias de los estudiantes y avances de las instituciones educativas, pretenden estandarizar los conocimientos de los educandos, olvidando el contexto en que se encuentran los pobladores, el nivel socioeconómico y cultural en el que se desenvuelven. 
Un conjunto decididamente heterogéneo que comprende discursos, investigaciones, instituciones, instalaciones, decisiones reglamentarias, leyes, medidas administrativas, enunciados científicos.

Educación y Ciencia - Núm 21 . AÑo 2018 • Pág. 145 - 171 una manera específica, constituyen un mecanismo destinado a producir unos resultados esperados.

Este término es usado por primera vez en la filosofía por Michel Foucault, en su obra monumental Arqueología del Saber; y aunque allí no lo definió, en su libro Saber y Verdad, lo estableció como

Un conjunto decididamente heterogéneo que comprende discursos, investigaciones, instituciones, instalaciones, decisiones reglamentarias, leyes, medidas administrativas, enunciados científicos. Proposiciones filosóficas, morales o filantrópicas. Los elementos del dispositivo pertenecen tanto a lo dicho como a lo no dicho. Es la red que puede establecerse entre dichos elementos (Foucault, 1977, p. 183).

Un dispositivo es, por tanto, el resultado de un entramado de relaciones entre saberes y poderes, anudamientos, dispersiones, que se configuran como un campo de relación de fuerzas. El dispositivo es la red que puede establecerse entre varios elementos y soportan diferentes tipos de saber. La noción de dispositivo es usada de diferentes formas y en diferentes situaciones.

En dicho marco se concibe la escuela como un entramado resultado de normatividades, metodologías, saberes, autoridades y relaciones que constituyen el sustrato de lo pedagógico, esto es, lo pedagógico se gesta en la escuela, se define en función del saber, desde lugares asimétricos entre el maestro y el estudiante, y, por tanto, se establecen relaciones de poder y saber (González et al., 2007), en el cual se desarrollan los procesos de enseñanza y aprendizaje; en el seno de estos procesos se utilizan un sinnúmero de estrategias, metodologías, didácticas particulares, experiencias de docentes, contextos y otros que se articulan de diferentes maneras, que según Foucault, se entrelazan constituyendo un dispositivo pedagógico.

Para Meirieu (1997), un dispositivo pedagógico es un conjunto de recursos que contribuyen al desarrollo de competencias en el campo de su hacer y saber; es una herramienta que pone en relación diferentes elementos contextuales, espaciales, e históricos, que se caracteriza por ser productor de transformaciones y facilitador del hacer y el crear; debe ser revelador en el sentido de desplegar significados; debe permitir el análisis y ser un organizador de saberes.

Mediante este dispositivo, el docente puede ser un generador de cambios a partir de la realidad contextual, donde saberes y poderes se enlazan generando nuevas relaciones de enseñanza y aprendizaje dentro y fuera del aula. Es de aclarar que acá el concepto de poder no se refiere a dominación sino a relaciones de fuerzas entre saberes rurales y académicos que constituyen una fortaleza del dispositivo $y$ contribuyen al enriquecimiento de unos saberes integrales.

\section{Ruralidad}

El término ruralidad no se presenta con una definición clara y específica 
del concepto que se quiere expresar. Aunque el concepto de ruralidad se ha venido empleando en publicaciones y artículos para hacer referencia al conjunto de los fenómenos sociales, políticos, económicos y culturales que se desarrollan en un entorno rural y que permiten construir identidad, el DANE (Departamento Administrativo Nacional de Estadística) representa la zona Rural como la disposición dispersa de viviendas y explotaciones agropecuarias existentes en ella. No cuenta con un trazado o nomenclatura de calles, carreteras, avenidas y demás, tampoco dispone por lo general de servicios públicos y otro tipo de facilidades propias de las áreas urbanas (Departamento Administrativo Nacional de Estadística, DANE, 2000).

Kayser (citado en Echeverry, 2011) define el espacio rural como:

Un conjunto territorial cuyas decisiones se le escapan y en el que existe un modo particular de utilización del espacio y de vida social, caracterizado, en primer lugar, por una densidad relativamente débil de habitantes y de construcciones, lo que determina un predominio de los paisajes vegetales; en segundo lugar, por un uso económico del suelo de predominio agrosilvo-pastoril; en tercer lugar, por un modo de vida de sus habitantes marcado por su pertenencia a colectividades de tamaño limitado, en las que existe un estrecho conocimiento personal y fuertes lazos sociales, y por su relación particular con el espacio, que favorece un entendimiento directo y vivencial del medio ecológico y, finalmente, por una identidad y una representación específicas muy relacionadas con la cultura campesina.

Últimamente, aparece un nuevo enfoque denominado nueva ruralidad, desde el cual se observan las realidades rurales en el marco de la globalización, entendida esta como la suma de procesos económicos y socioculturales que atraviesan las identidades de las familias campesinas y revaloran su posición en el mercado, en términos de participación en ocupaciones agrícolas y no agrícolas.

\section{Competencias}

Tardif (citado en Cázares \& Gallardo, 2010) señala que el concepto de competencias es polisémico, por tal motivo no existe entre los especialistas en educación un consenso sobre lo que significa este término, por el contrario, "existen al menos dos concepciones de competencias, una de corte conductual cercana a las propuestas de orden laboral y otra de corte sistémico que se ha anclado en las perspectivas cognitivas" (Díaz Barriga, 2011).

En esta investigación se tuvo en cuenta el horizonte conceptual de Tobón en lo referente a competencias. Estas son actuaciones generales ante actividades y problemas del contexto con metacognición, idoneidad y ética. Son la concreción de la formación humana integral y se integran al proyecto ético de vida. Consideran los grandes propósitos de formación establecidos en un país, un estado o una institución (Tobón, 2013). Según este autor, las Competencias Básicas son las competencias fundamentales para vivir
Un conjunto territorial cuyas decisiones se le escapan y en el que existe un modo particular de utilización del espacio y de vida social, caracterizado, en primer lugar, por una densidad relativamente débil de habitantes y de construcciones, lo que determina un predominio de los paisajes vegetales; en segundo lugar, por un uso económico del suelo de predominio agro-silvo-pastoril 


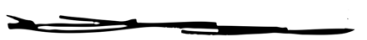

Los procesos implicados en esta competencia se basan en escoger caminos cortos para solucionar un problema y hallar la solución más adecuada de acuerdo con el contexto; establecimiento de regularidades y generalizaciones en sociedad y desenvolverse en cualquier ámbito laboral. Estas competencias se caracterizan por: (1) constituyen la base sobre la cual se forman los demás tipos de competencias; (2) se forman en la educación básica y media; (3) posibilitan analizar, comprender y resolver problemas de la vida cotidiana; (4) constituyen un eje central en el procesamiento de la información de cualquier tipo. Las competencias básicas son la interpretativa, la argumentativa y la propositiva (Tobón, 2013).

Competencia interpretativa. Se fundamenta en la comprensión de la información buscando determinar su sentido y significación a partir del análisis de textos, gráficas, expresiones musicales, esquemas, teatro, gestos y expresiones orales. Los subprocesos en la actividad desarrollada, entendimiento del sentido dentro de un contexto, identificación de un problema reconociendo sus diferentes elementos, establecimiento de relaciones entre procesos, establecimiento de información relevante para resolver un problema (Tobón, 2013).

Competencia argumentativa. Consiste en un conjunto de habilidades, conocimientos y actitudes dirigidas a la explicación de determinados procesos, proposiciones, tesis, planteamientos, procedimientos, teorías, sucesos, anécdotas, mitos, fenómenos naturales y sociales. Los subprocesos implicados en esta competencia son la hilación de los conceptos con base en un propósito comunicativo específico, derivar implicaciones de teorías y teorizar sobre determinado hecho (Tobón, 2013).
Competencia propositiva. Consiste en proponer hipótesis para explicar determinados hechos; construir soluciones a los problemas; deducir las consecuencias de un determinado procedimiento; elaborar unos determinados productos (Tobón, 2013).

Los procesos implicados en esta competencia se basan en escoger caminos cortos para solucionar un problema y hallar la solución más adecuada de acuerdo con el contexto; establecimiento de regularidades y generalizaciones (Tobón, 2013).

\section{Metodología}

\section{Enfoque y tipo de investigación}

Esta investigación se desarrolló con el enfoque cualitativo, que permite entender los diferentes significados que los sujetos a investigar dan a sus actos, experiencias y situaciones contextuales en las que se encuentran inmersos; comprender dicho contexto y las influencias de estos sobre los sujetos; identificar fenómenos y desarrollar explicaciones válidas de fenómenos no cuantificables (Maxwell, 1996).

En el marco del enfoque cualitativo, se utilizó el tipo de investigación Investigación - Acción propuesto por Elliott (citado en García, 2010), quien propone las siguientes fases: identificación de una situación problemática mediante un diagnostico; diseño e implementación de una estrategia con el objetivo de darle solución a dicha problemática; y, por último, la evaluación de la 
Tabla 1. Competencias evaluadas por el ICFES

\begin{tabular}{|c|c|c|c|}
\hline Competencia & $\begin{array}{c}\text { Subprocesos } \\
\text { implicados }\end{array}$ & $\begin{array}{l}\text { Criterios de } \\
\text { idoneidad }\end{array}$ & Acciones específicas \\
\hline $\begin{array}{l}\text { Interpretativa: Se } \\
\text { fundamenta en la } \\
\text { comprensión de la } \\
\text { información buscando } \\
\text { determinar su sentido } \\
\text { y significación a partir } \\
\text { del análisis de textos, } \\
\text { gráficas, expresiones } \\
\text { musicales, esquemas, } \\
\text { teatro, gestos y } \\
\text { expresiones orales. }\end{array}$ & $\begin{array}{l}\text { En la actividad } \\
\text { desarrollada, } \\
\text { entendimiento del } \\
\text { sentido dentro } \\
\text { de un contexto, } \\
\text { identificación } \\
\text { de un problema, } \\
\text { reconocimiento } \\
\text { de diferentes } \\
\text { elementos de } \\
\text { un problema, } \\
\text { establecimiento } \\
\text { de relaciones } \\
\text { entre procesos, } \\
\text { establecimiento } \\
\text { de información } \\
\text { relevante para } \\
\text { resolver un } \\
\text { problema. }\end{array}$ & $\begin{array}{l}\text { Comprensión del } \\
\text { mensaje acorde } \\
\text { con el contexto, } \\
\text { relación de la nueva } \\
\text { información con los } \\
\text { saberes previos. }\end{array}$ & $\begin{array}{l}\text { Interpretar datos: } \\
\text { Comprender } \\
\text { proposiciones y párrafos. } \\
\text { Identificar } \\
\text { argumentos, ejemplos, } \\
\text { contraejemplos y } \\
\text { demostraciones. } \\
\text { Comprender problemas. } \\
\text { Interpretar cuadros, } \\
\text { tablas, gráficos, } \\
\text { diagramas, dibujos y } \\
\text { esquemas. } \\
\text { Interpretar mapas, } \\
\text { planos y modelos. }\end{array}$ \\
\hline $\begin{array}{l}\text { Argumentativa: } \\
\text { Consiste en } \\
\text { un conjunto } \\
\text { de habilidades, } \\
\text { conocimientos y } \\
\text { actitudes dirigidas } \\
\text { a la explicación de } \\
\text { determinados procesos, } \\
\text { proposiciones, tesis, } \\
\text { planteamientos, } \\
\text { procedimientos, teorías, } \\
\text { sucesos, anécdotas, } \\
\text { mitos, fenómenos } \\
\text { naturales y sociales. }\end{array}$ & $\begin{array}{l}\text { Ilación de los } \\
\text { conceptos con base } \\
\text { en un propósito } \\
\text { comunicativo } \\
\text { específico. Derivar } \\
\text { implicaciones de } \\
\text { teorías. Teorizar } \\
\text { sobre determinado } \\
\text { hecho. }\end{array}$ & $\begin{array}{l}\text { Coherencia en } \\
\text { los argumentos. } \\
\text { Sujeción a pruebas } \\
\text { y hechos que los } \\
\text { demás pueden } \\
\text { constatar. Sencillez } \\
\text { en el discurso. } \\
\text { Lógica. }\end{array}$ & $\begin{array}{l}\text { Explicar el por qué, } \\
\text { cómo y para qué. } \\
\text { Demostrar hipótesis. } \\
\text { Comprobar hechos. } \\
\text { Presentar ejemplos y } \\
\text { contraejemplos. } \\
\text { Articular conceptos. } \\
\text { Sustentar conclusiones. }\end{array}$ \\
\hline $\begin{array}{l}\text { Propositiva: Consiste } \\
\text { en proponer hipótesis } \\
\text { para explicar } \\
\text { determinados hechos; } \\
\text { construir soluciones a } \\
\text { los problemas; deducir } \\
\text { las consecuencias } \\
\text { de un determinado } \\
\text { procedimiento; } \\
\text { elaborar unos } \\
\text { determinados } \\
\text { productos. }\end{array}$ & $\begin{array}{l}\text { Establecimiento de } \\
\text { heurísticos (caminos } \\
\text { cortos para resolver } \\
\text { un problema). } \\
\text { Planteamiento de } \\
\text { procedimientos } \\
\text { para resolver } \\
\text { los problemas y } \\
\text { hallar la solución } \\
\text { más adecuada } \\
\text { de acuerdo con } \\
\text { el contexto. } \\
\text { Establecimiento } \\
\text { de regularidades y } \\
\text { generalizaciones. }\end{array}$ & $\begin{array}{l}\text { Claridad en la } \\
\text { resolución de } \\
\text { problemas. Hipótesis } \\
\text { científicas. Lógica en } \\
\text { las ideas propuestas. }\end{array}$ & $\begin{array}{l}\begin{array}{l}\text { Planear y resolver } \\
\text { problemas. }\end{array} \\
\text { Formular proyectos. } \\
\text { Generar hipótesis. } \\
\text { Descubrir regularidades. } \\
\text { Hacer generalizaciones. } \\
\text { Construir modelos. }\end{array}$ \\
\hline
\end{tabular}

Fuente: adaptado Tobón (2013) y Salas (2005). 
implementación en la estrategia.

\section{Instrumentos para la recolección de información y técnicas de análisis}

Los instrumentos que se utilizaron para la recolección de información, fueron: sustentaciones individuales y grupales, entrevistas semiestructuradas, observaciones, fotografías y grabaciones. Dicha información fue analizada mediante triangulación, observación directa e interpretación.

\section{Fases de la investigación}

En el marco de la investigación-acción, se desarrollaron tres fases: el diagnóstico, la aplicación de una estrategia para solucionar la problemática identificada en el diagnóstico y, por último, la evaluación del resultado obtenido en la aplicación de la estrategia.

Fase 1: Diagnóstico. Siguiendo los pasos del proceso de investigación-acción, se realizó un diagnóstico para establecer las posibles causas de las deficiencias en las competencias básicas, en dos momentos: en un primer momento, se aplicó una encuesta a los tres estamentos de la institución educativa: directivos, docentes y estudiantes; en un segundo momento, se aplicó un test diagnóstico a los estudiantes, el cual estaba estructurado con preguntas de las pruebas saber aplicadas en años anteriores tomado del banco del ICFES. Es de aclarar que, este proyecto es transversal realizado por los docentes de las asignaturas de matemáticas, ciencias naturales y sociales;

por esta razón, el diagnóstico se realizó teniendo en cuenta estas asignaturas. En la siguiente tabla se muestra las encuestas realizadas a directivos, docentes y estudiantes en el proceso de diagnóstico.

Tabla 2. Encuestas diagnósticas realizadas a directivos, docentes y estudiantes

\begin{tabular}{llll}
\hline Competencia & $\begin{array}{l}\text { Pregunta a } \\
\text { estudiantes }\end{array}$ & Pregunta a docentes & Pregunta a directivos \\
\hline
\end{tabular}




\begin{tabular}{|c|c|c|c|}
\hline \multirow[b]{2}{*}{ Interpretativa } & $\begin{array}{l}\text { 1. ¿Por qué algunas } \\
\text { veces no entiende } \\
\text { los problemas de } \\
\text { matemáticas, sociales } \\
\text { o química, que } \\
\text { sus profesores les } \\
\text { plantean? }\end{array}$ & $\begin{array}{l}\text { ¿Cómo cree que influye la } \\
\text { competencia interpretativa } \\
\text { en el aprendizaje de } \\
\text { sus estudiantes en } \\
\text { las asignaturas de } \\
\text { matemáticas, sociales o } \\
\text { química? }\end{array}$ & $\begin{array}{l}\text { ¿Considera que el } \\
\text { docente de su colegio } \\
\text { tiene claridad sobre el } \\
\text { papel que desempeña } \\
\text { el desarrollo de la } \\
\text { competencia interpretativa } \\
\text { en el aprendizaje de los } \\
\text { estudiantes? }\end{array}$ \\
\hline & $\begin{array}{l}\text { 2. Explique tres } \\
\text { razones por las cuales } \\
\text { algunas veces no } \\
\text { opina en clase sobre } \\
\text { los textos, mapas } \\
\text { o problemas de } \\
\text { matemáticas o química. }\end{array}$ & $\begin{array}{l}\text { En su opinión, ¿cuáles } \\
\text { podrían ser la causas por } \\
\text { las cuales algunos de sus } \\
\text { estudiantes no interpretan } \\
\text { correctamente mapas, } \\
\text { gráficas, problemas o } \\
\text { textos de las asignaturas } \\
\text { mencionadas en la } \\
\text { pregunta uno? }\end{array}$ & $\begin{array}{l}\text { En su opinión, ¿cuáles } \\
\text { serían causas de las } \\
\text { dificultades que presentan } \\
\text { algunos estudiantes } \\
\text { en la interpretación de } \\
\text { diferentes textos, gráficos, } \\
\text { tablas y problemas? }\end{array}$ \\
\hline \multirow[t]{2}{*}{ Argumentativa } & $\begin{array}{l}\text { 3. Si se le dificulta } \\
\text { explicar cómo } \\
\text { desarrolla un problema } \\
\text { de matemáticas, dé tres } \\
\text { razones de ello. }\end{array}$ & $\begin{array}{l}\text { ¿En dónde cree que } \\
\text { radican las causas de las } \\
\text { dificultades que presentan } \\
\text { algunos estudiantes para } \\
\text { argumentar el por qué y el } \\
\text { cómo de un procedimiento } \\
\text { en asignaturas abstractas } \\
\text { como matemáticas o } \\
\text { química. }\end{array}$ & $\begin{array}{l}\text { En su percepción, ¿cuáles } \\
\text { serían las causas por las } \\
\text { cuáles algunos estudiantes } \\
\text { presentan dificultades en } \\
\text { el razonamiento lógico } \\
\text { aplicado a asignaturas } \\
\text { abstractas? }\end{array}$ \\
\hline & $\begin{array}{l}\text { 4. ¿Cómo le gustaría } \\
\text { que su docente le } \\
\text { preguntara sobre el } \\
\text { cómo y por qué de sus } \\
\text { respuestas? }\end{array}$ & $\begin{array}{l}\text { ¿Cuáles son los } \\
\text { fundamentos teóricos } \\
\text { que sustentan su práctica } \\
\text { en pro del desarrollo } \\
\text { de la competencia } \\
\text { argumentativa? }\end{array}$ & $\begin{array}{l}\text { ¿Cuáles son, en su } \\
\text { opinión, los fundamentos } \\
\text { teóricos que sustentan } \\
\text { la praxis de los docentes } \\
\text { en el desarrollo } \\
\text { de la competencia } \\
\text { argumentativa? }\end{array}$ \\
\hline
\end{tabular}


Propositiva

\begin{tabular}{|c|c|}
\hline $\begin{array}{l}\text { 7. ¿Le gustaría que } \\
\text { sus profesores les } \\
\text { explicaran con } \\
\text { ejemplos de situaciones } \\
\text { del medio donde usted } \\
\text { vive? }\end{array}$ & $\begin{array}{l}\text { ¿Cree usted que al } \\
\text { involucrar el contexto } \\
\text { rural de los estudiantes } \\
\text { en la enseñanza de las } \\
\text { asignaturas mencionadas } \\
\text { facilitaría el desarrollo de } \\
\text { competencias básicas? Dé } \\
\text { tres razones. }\end{array}$ \\
\hline $\begin{array}{l}\text { gustaría que } \\
\text { in solo ejemplo } \\
\text { do del medio } \\
\text { e usted vive se }\end{array}$ & $\begin{array}{l}\text { ¿Está de acuerdo } \\
\text { con un aprendizaje } \\
\text { interdisciplinario entre las } \\
\text { asignaturas mencionadas? } \\
\text { ¿Por qué? }\end{array}$ \\
\hline
\end{tabular}

En su opinión, ¿cuáles son las maneras en que los docentes, en el marco del currículo, integran las situaciones académicas problemáticas en la búsqueda de diferentes alternativas de solución por parte de los estudiantes?

$¿$ Considera que las maneras de solución de situaciones problemáticas del contexto de los estudiantes muestra el desarrollo adecuado de competencias básicas que se pretenden desarrollar en las asignaturas de Matemáticas, Química o Geografía?

$¿$ Considera que los docentes realizan los procesos de enseñanza y aprendizaje teniendo en cuenta el contexto de la I.E.? ¿Cómo lo evidencian?

¿En los procesos curriculares de su Institución se evidencian metodologías de aprendizajes interdisciplinarios? ¿Cuáles?

Fuente: elaboración propia. 
La siguiente tabla muestra el resumen de la triangulación por estamento de las encuestas utilizadas como diagnóstico donde se establecen las posibles causas de dicha deficiencia:

Tabla 3. Triangulación por estamento

\section{ESTUDIANTES}

\begin{tabular}{|c|c|}
\hline \multicolumn{2}{|c|}{ Interpretativa } \\
\hline - & $\begin{array}{l}\text { Desconocimiento } \\
\text { vocabulario. }\end{array}$ \\
\hline - & $\begin{array}{l}\text { No existe relación entre } \\
\text { los conocimientos } \\
\text { académicos y el contexto. }\end{array}$ \\
\hline - & $\begin{array}{l}\text { Falta de transitividad } \\
\text { entre los conocimientos } \\
\text { previos y los nuevos. }\end{array}$ \\
\hline- & $\begin{array}{l}\text { Deficiencia de } \\
\text { conocimientos previos } \\
\text { estructurados. }\end{array}$ \\
\hline - & $\begin{array}{l}\text { No reconocen causas y } \\
\text { consecuencias de una } \\
\text { problemática planteada. }\end{array}$ \\
\hline & $\begin{array}{l}\text { Existe en algunos casos } \\
\text { falta de tolerancia con los } \\
\text { compañeros en el ámbito } \\
\text { de la clase. }\end{array}$ \\
\hline
\end{tabular}

\section{Argumentativa}

- Se le dificulta seguir un proceso lógico en la solución de un problema, lo que trae como consecuencia la imposibilidad para explicar con lógica una solución dada.

\section{DOCENTES}

\section{Interpretativa}

\section{Propositiva}

- No logra colocar en contexto los conocimientos académicos, no proponen alternativas diferentes a la expuesta por el docente a la solución de problemas, no relacionan los procesos académicos con la solución de problemas de contexto y personales.

- Todas estas características identifican deficiencias en las competencias básicas de los estudiantes (Tobón, 2005). 
- Los docentes recalcan la importancia de la competencia interpretativa, para darle sentido a la cotidianidad y establecen como causa de su deficiencia a la pereza, poco manejo de vocabulario y falta de interés de los estudiantes.
- Con respecto a la competencia argumentativa, afirman que los estudiantes no dan razones del porqué de sus respuestas, por falta de análisis y deficiencia de vocabulario para expresar sus puntos de vista.

\section{DIRECTIVOS}

\section{Interpretativa}

Argumentativa

- Los docentes no identifican claramente las deficiencias en la competencia propositiva, pero dan algunas sugerencias de cómo relacionar los conocimientos académicos con el contexto en pro de su desarrollo.

\section{Propositiva}


- Con respecto el concepto, - La deficiencia se no existe claridad ni apropiación contextual ni metodológica de la competencia interpretativa por parte de los docentes, lo que permite la falta de estructuración en las acciones pedagógicas para adquirirla. encuentra en que los estudiantes no cuentan con bases conceptuales para enfrentar un problema mediante la lógica aplicada.
Fuente: elaboración propia.

A continuación, se presenta la tabla resumen de la triangulación final entre los tres estamentos, que muestra las posibles causas de la deficiencia en competencias básicas.

\section{Tabla 4. Triangulación final entre} estamentos.
Argument
- A pesar de que la mayoría de docentes integran situaciones académicas a situaciones problemáticas del contexto a través de la transversalidad de los proyectos pedagógicos, algunos estudiantes no logran contextualizar lo aprendido en clase con su diario vivir.

- No entienden debido a la falta de interés en los temas, terminología desconocida, falta de significación a la actividad académica.

- No se tiene en cuenta el contexto de la institución, se evidencian puesto que no se hacen diagnósticos reales y completos sobre las

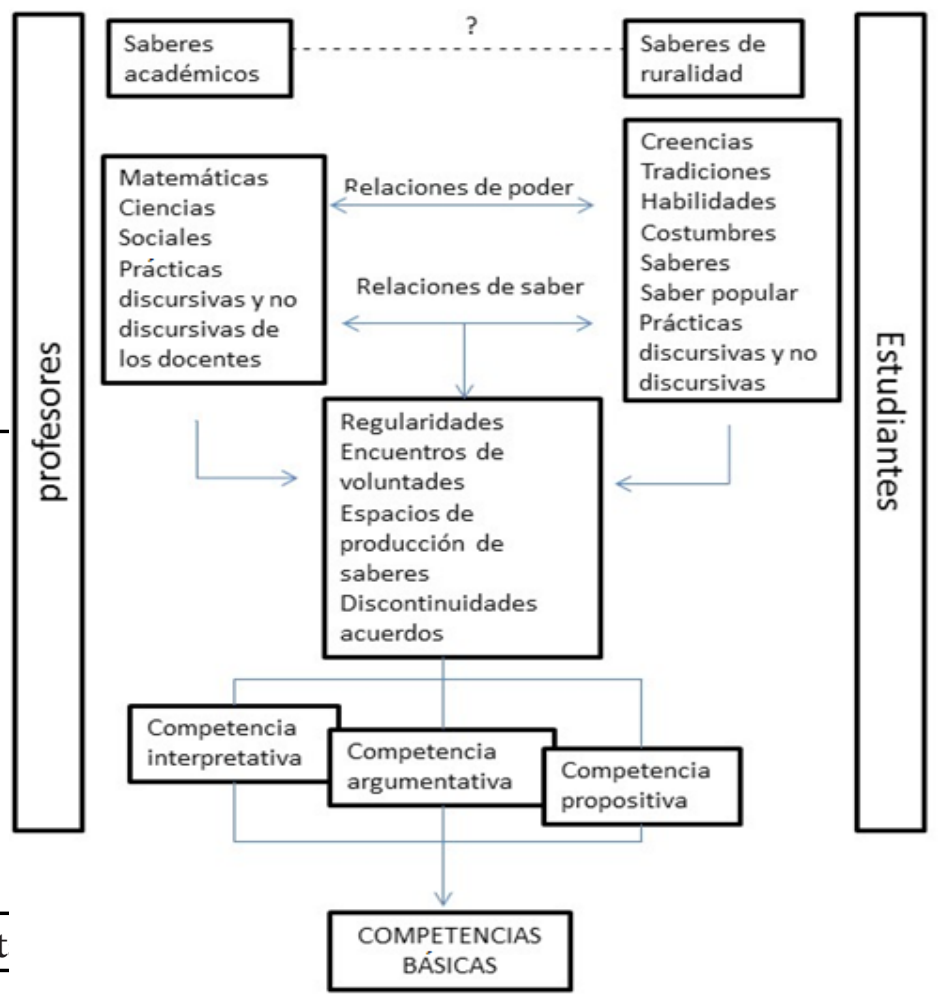

Figura 1. Dispositivo Pedagógico.

Fuente: elaboración propia. 
Las posibles causas de la deficiencia de la competencia son: falta de claridad, apropiación contextual y metodológica de la competencia por parte de los docentes, lo que ocasiona la deficiencia de estructuración en las acciones pedagógicas para adquirirla. Además, los estudiantes manifiestan pereza, poco interés en las clases, desconocimiento de vocabulario, no existe relación entre los conocimientos académicos y el contexto, falta de transitividad entre los conocimientos previos y los nuevos, muestran dificultad en reconocer causas y consecuencias de una problemática planteada y existe en algunos casos falta de tolerancia con los compañeros en el ambiente de la clase.

La deficiencia se A pesar de que la mayoría de docentes integran

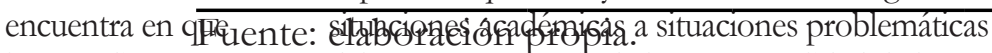
los estudiantes del contexto a través de la transversalidad de los

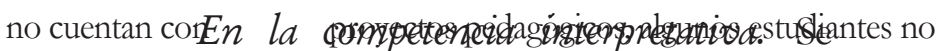

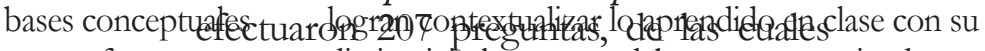

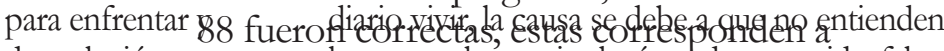

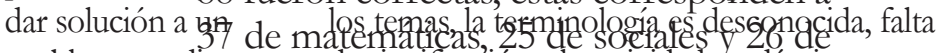
problema mediante de sionificación a la actividad académica y como

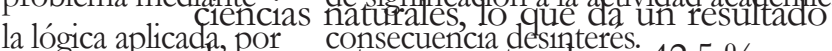
la lógica aplicada, por consecuencia desinteres. $42,5 \%$.

ende no da razones Los estudiantes en determinadas ocasiones

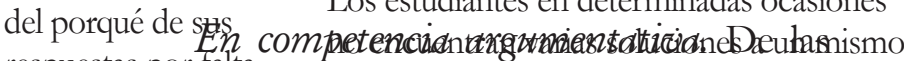

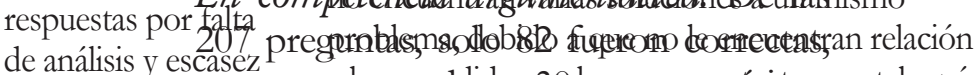

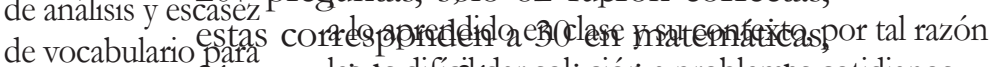

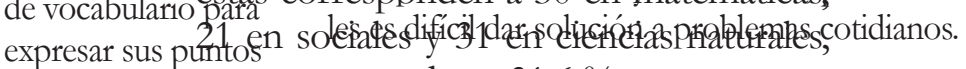

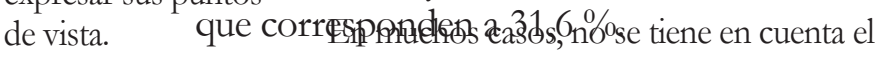
contexto de la institución, no se hacen diagnósticos

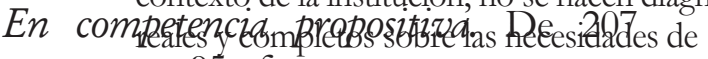

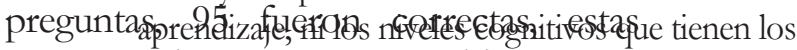

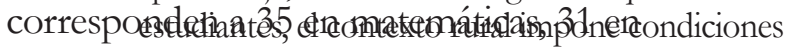

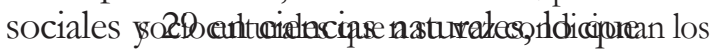

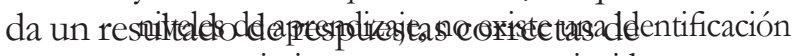
un 45,9 $y_{0}$ un seguimiento a esos aspectos incidentes y condicionantes.

Fuente: elaboración propia.

En el segundo momento se aplicó el test a 23 estudiantes de grado octavo de la Institución Educativa, con el objeto detectar las deficiencias en el desarrollo de competencias básicas. El resultado de este test se resume en la siguiente tabla.

Entre los saberes académicos y los de la ruralidad, existen discontinuidades evidenciadas como rupturas o quiebres, que muchas veces se superponen o se oponen haciendo predominar unos saberes sobre los otros.

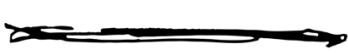

\begin{tabular}{cc}
\hline COMPETENCIAS & MATEMÁ- \\
BÁSICAS & TICAS
\end{tabular}

COMPETENCIA
INTERPRETATIVA

COMPETENCIA
COMPETENCIA PROPOSITIVA

37

30

35

\section{Tabla 5. Resultados diagnóstico test
de competencias básicas \\ Tabla 5. Resultados diagnóstico tes
de competencias básicas}

En total, el test constaba de 27 preguntas aplicada a 23 estudiantes, lo que daría un total 621 preguntas, de las cuales 265 se contestaron de forma correcta, que corresponde a un $42.7 \%$ de acierto del grupo. Lo anterior evidencia que existen falencias en el desarrollo de competencias básicas.

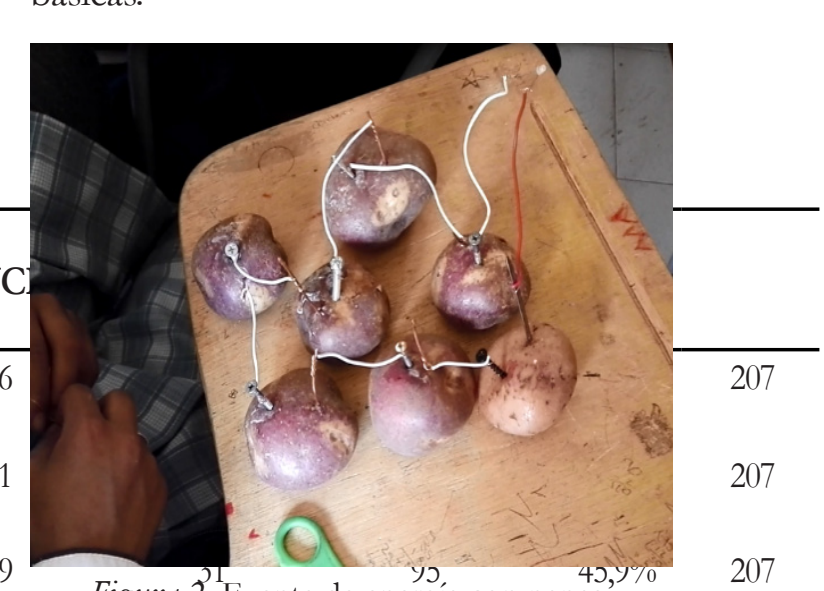

Figura 2. Fuente de energía con papas. Fuente: elaboración propia. 
265 Conłel topjeto des contribuir en la solución de esta problemática, se diseñó una estrategia que involucra los saberes académicos de las asignaturas de ciencias naturales, ciencias sociales y matemáticas con los saberes de contexto de los estudiantes alrededor de la historia, el cultivo y posibles aplicaciones de uno de los cultivos autóctonos: LA PAPA.

En el marco de los referentes teóricos anteriores y la metodología de investigación- acción, se elaboró el Dispositivo Pedagógico en el que se entrelazan los conceptos aparentemente heterogéneos de ruralidad, competencias $\mathrm{y}$ dispositivo, pero que constituyen un entramado entre los saberes académicos, saberes de los docentes con sus prácticas, saberes rurales de los estudiantes como costumbres, tradiciones, creencias y experiencias; que, anudados por diferentes tipos de relaciones entre saberes y relaciones asimétricas de poder, permiten explicar las formas y los sentidos que construyen los estudiantes entre la cotidianidad rural y las asignaturas de la institución permitiendo una serie de relaciones como insumos para adentrarse en comprensiones, explicaciones y posibles respuestas a situaciones que vayan más allá de los conocimientos académicos: competencias básicas. $\mathrm{El}$ modelo que se propone como un cúmulo de relaciones entre los conocimientos académicos y la ruralidad, se expresa en el siguiente diagrama:

En dicho modelo de dispositivo, existe un cúmulo de relaciones generando fuerzas de poder entendidas estas como reacciones naturales que se establecen en cualquier relación. Para Foucault (1977), el poder no pasa por el enfrentamiento entre dominantes y dominados, sino por relaciones de acciones y reacciones múltiples. En esta concepción, el poder es ubicuo, se desliza y está presente en cada intersticio del entramado social de la escuela.

Deotraparte, encadaunodelos contextos de la ruralidad y la institución, existen ciertos saberes que se han establecido mediante regularidades que han sido aceptadas como sus propias "verdades", transformadas mediante prácticas entendidas estas como actividades que transforman sus realidades y naturalizan lo que se debe decir en un contexto o en una época determinada, esto es, establecen las "verdades" de lo que Existen normatividades, reglamentos y políticas que influyen sobre las practicas discursivas). se constituyen en las "verdades" de lo que se debe hacer (Foucault, 1977).

Entre los saberes académicos y los de la ruralidad, existen discontinuidades evidenciadas como rupturas o quiebres, que muchas veces se superponen o se oponen haciendo predominar unos saberes sobre los otros. Es posible buscar conexiones entre estas discontinuidades que se complementen mediante encuentro de voluntades, de tal manera que las fuerzas de poder entre saberes académicos y de ruralidad se conviertan en espacios de producción de conocimientos integrales, tanto de maestros como estudiantes, que conlleven al desarrollo de capacidades interpretativas, argumentativas y propositivas; en este entramado, el poder no obstaculiza el saber sino que contribuye a su construcción.

Mediante este dispositivo, el docente se convierte en un generador de cambios a partir de la realidad contextual donde saberes y poderes se enlazan generando nuevas relaciones de enseñanza y aprendizaje. Dicho modelo se materializó en el contexto de la Institución a través de la historia, cultivo y procesos de producción, distribución y consumo de Papa, mediados por las áreas de matemáticas, sociales y ciencias naturales. 159

Educación y Ciencia - Núm 21. AÑo 2018 • PÁa. 145 - 171 
A continuación, se describen las actividades que se desarrollaron en el marco de la estrategia desarrollada.

En ciencias naturales. Se realizó una experiencia que buscó comprender el concepto de electricidad, para lo cual se utilizó como fuente de energía varias papas, a través de un circuito electrónico conectado en serie para encender un diodo emisor de luz.

Al iniciar la actividad, se plantean preguntas a los estudiantes: ¿por qué un bombillo ilumina?, ¿será posible encender un bombillo utilizando papas?, estas preguntas se respondieron luego de realizar el experimento. Al entregar a los estudiantes los materiales para montar la pila o batería de papas, estos siguieron las instrucciones dadas, expusieron los resultados obtenidos y explicaron por qué y cómo se realizó el experimento. Analizaron si la información que obtuvieron era suficiente para contestar preguntas o sustentar explicaciones del trabajo que realizaron. Plantearon y resolvieron los problemas que se presentaron durante el desarrollo de la actividad. Sacaron conclusiones del experimento que realizaron, aunque algunos no obtuvieron los resultados esperados (Tobón, 2005). En la competencia argumentativa, los alumnos elaboraron un circuito en serie empleando diferentes papas para hacer funcionar un led o reloj, y propusieron soluciones a los problemas que se presentaron para el funcionamiento del experimento.

Para el cierre de la actividad, los estudiantes contestaron las preguntas iniciales. Según Tobón (2005), la competencia propositiva se desarrolló a partir del resultado donde los alumnos plantean que existen diversas fuentes y formas de energía como limones, tomates y que estas se transforman continuamente de energía química a energía eléctrica. Además, reconocen los instrumentos que permiten medir la corriente

eléctrica y el voltaje.

Para finalizar, se realizó una evaluación grupal. En ella, los estudiantes de una parte infirieron que las papas tienen un fluido en su interior, que permite el flujo de electrones generando electricidad; y de otra, evidenciaron el potencial que existe en su entorno rural en el desarrollo de capacidades interpretativas, argumentativas $\mathrm{y}$ propositivas, pues descubrieron que son capaces desde su contexto de proponer iniciativas que antes ignoraban.
Analizando cada proceso llevado a cabo y teniendo en cuenta las respuestas y las diferentes actividades, se estableció la siguiente categorización, basados en Tobón (2005).

\section{Tabla 6. Categorías Competencias Básicas en Ciencias Naturales.}


Reconoce explicaciones posibles, con base en el conocimiento cotidiano del contexto.

Identifica variables que influyen en los resultados de un experimento empleando como fuente de energía papas.

Comprende la naturaleza de los fenómenos relacionados con la electricidad y el magnetismo.

Analiza si la información que he obtenido es suficiente para contestar mis preguntas o sustentar mis explicaciones.

Saca conclusiones de los experimentos que realiza, aunque no obtenga los resultados esperados.

Analiza el desarrollo de los componentes de los circuitos eléctricos y su impacto en la vida diaria.

Propone soluciones a los problemas que se presentan para el funcionamiento del experimento.

Plantea que existen diversas fuentes y formas de energía y que estas se transforman continuamente.

Relaciona voltaje y corriente con los diferentes elementos de un circuito eléctrico complejo y para todo el sistema.

Formula explicaciones posibles, con base en el conocimiento cotidiano del contexto.

Fuente: elaboración propia.

En Ciencias Sociales. En primer lugar, se realizó una entrevista abierta aplicada gor los estudiantes a sus familiares Categor etara de la papa, para lo cual, se plantearon preguntas pensando en el contexto rural Boyacense,

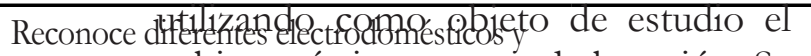
explica cómgultitiér máns importante de la región. Se pretendió que el estudiante y su grupo Sigue los pafampliaral peratioilondaln con base en sus

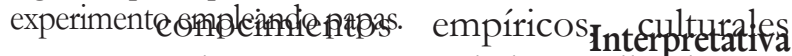
y de contexto en el desarrollo de esta entrevista. Una vez realizada, el docente

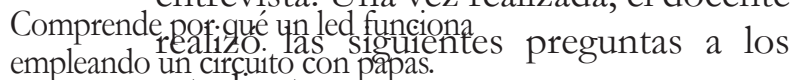
estudiantes:

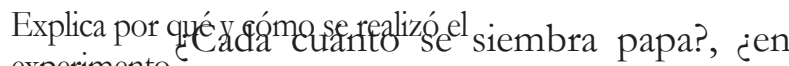
experimento qué meses se debe sembrar?, ¿por qué en esos meses?

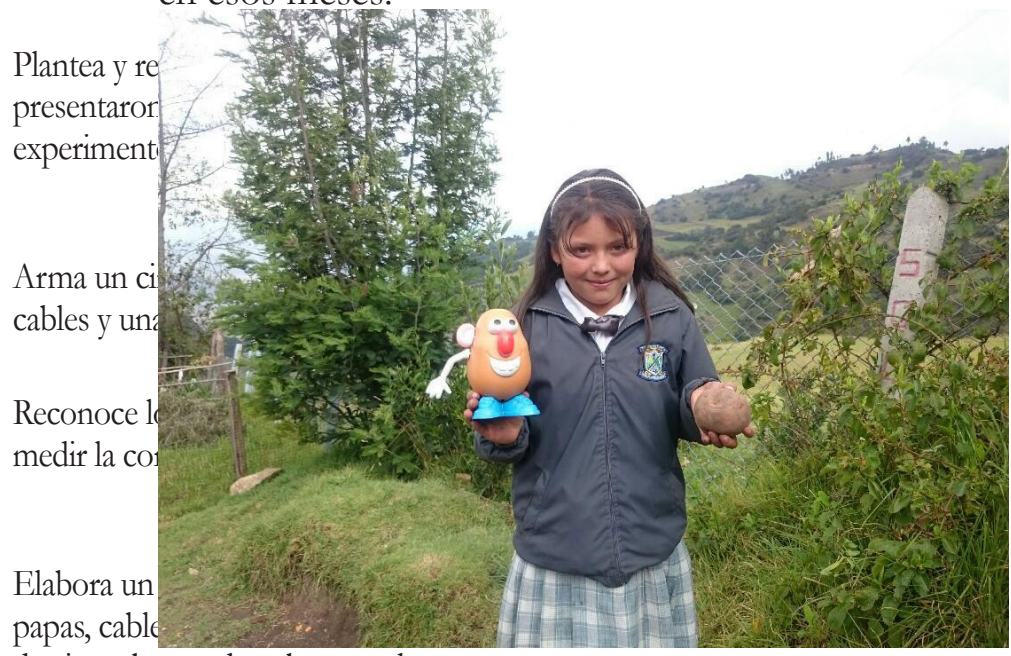

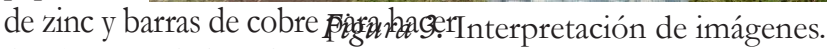

funcionar un led o reloj. $\quad$ Fuente: los Propositiva

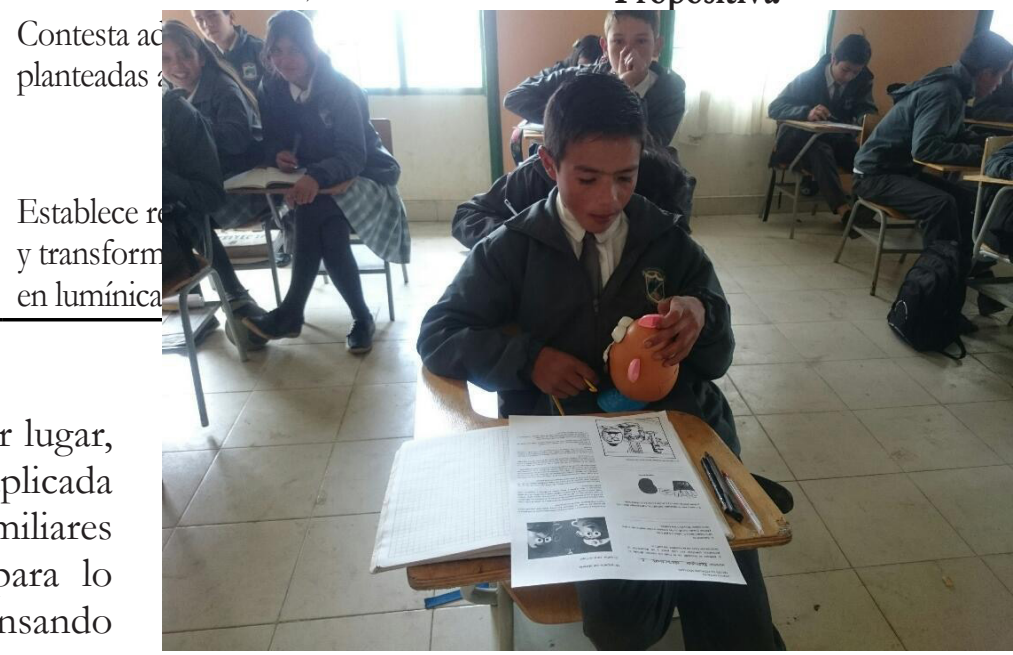

Figura 4. Comparación Contextual. Fuente: los autores. 
¿Por qué en la vereda solo se cultivan 3 o 4 clases de papa?

En las respuestas, los estudiantes expusieron y argumentaron con gran propiedad sus conocimientos aprendidos o escuchados de su familia sobre aspectos del cultivo, clases de papa, características, usos, y propusieron recetas novedosas, posibles usos en la industria, medicina, y experimentaron el gran potencial argumentativo demostrado a través de sus exposiciones, situación que evidencia relaciones de poder como aportes a la construcción de un saber.

También se tuvieron en cuenta como estrategia los relatos de experiencia de vida: que consisten en la descripción por parte de los estudiantes de situaciones reales vividas en la cotidianidad de la ruralidad y el cultivo de la papa mediante una entrevista y un video, este tipo de actividades despertó el interés de los estudiantes, llamó la atención, ya que al ser un tema del cual la mayoría tiene conocimiento es digno de ser contado y, lo más importante, se establecieron relaciones entre la institución educativa y el entorno.

Como actividades para favorecer la atención de los estudiantes, se manejaron preguntas intercaladas (Rickards, 1980), las cuales se insertan en la exposición de cada estudiante sobre su conocimiento del cultivo de la papa con el fin de atraer su atención y facilitar el aprendizaje, este tipo de ejercicios mantienen la atención sobre un tema en específico, fortalece la reflexión y la comprensión de la información. A su vez, se utilizaron imágenes para interpretar, como: caricaturas, gráficos y diálogos, ya que este tipo de recursos es llamativo, pues despiertan el interés y la concentración, y ayudan a comprender y proponer acciones en secuencia (Díaz \& Hernández Rojas, 1999).

Se logró una personalización de la información facilitando la iniciativa y la crítica, fomentando la formación de la competencia propositiva, elaborando un texto en forma de cuento cumpliendo con sus partes, relacionando el contexto, las realidades del cultivo de papa y la creatividad e imaginación de los jóvenes de grado octavo. Todas estas actividades mostraron encuentro de voluntades, voluntades de aprender, de enseñar y compartir saberes. 


\section{Tabla 7. Categorías Competencias Básicas en Ciencias Sociales}

Explica y Justifica los procesos de producción distribución y consumo relacionados con el cultivo de la papa en

\begin{tabular}{l} 
Patrón de respuesta \\
\hline Explican procedimientos y procesos de \\
adecuación y preparación del terreno \\
para el cultivo de la papa.
\end{tabular}

Comprende información escrita en lenguaje simple relacionada con temas del diario vivir.

Analiza algunas condiciones sociales, económicas, políticas y culturales de la región y las plasma en un escrito simple. el costubctategoría

Comprende problemas que se suscitan en torno al cultivo de la papa.

Establece relación entre los saberes de los estudiantes Explideatele empleo de terminado razonamiento en la resolución de Interpreta cuadros y graficos.
problemas de la vida diaria.

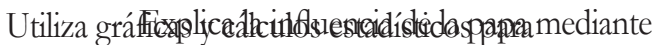
analizar in sumesón.

Reconoce Pulading ldifarentesiósos y aplicaciones

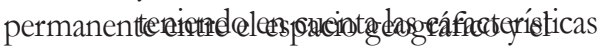
ser humanfísicas y químicas de la papa.
Responde al ¿por qué?, ¿cómo? y ¿para qué? de temas cotidianos.
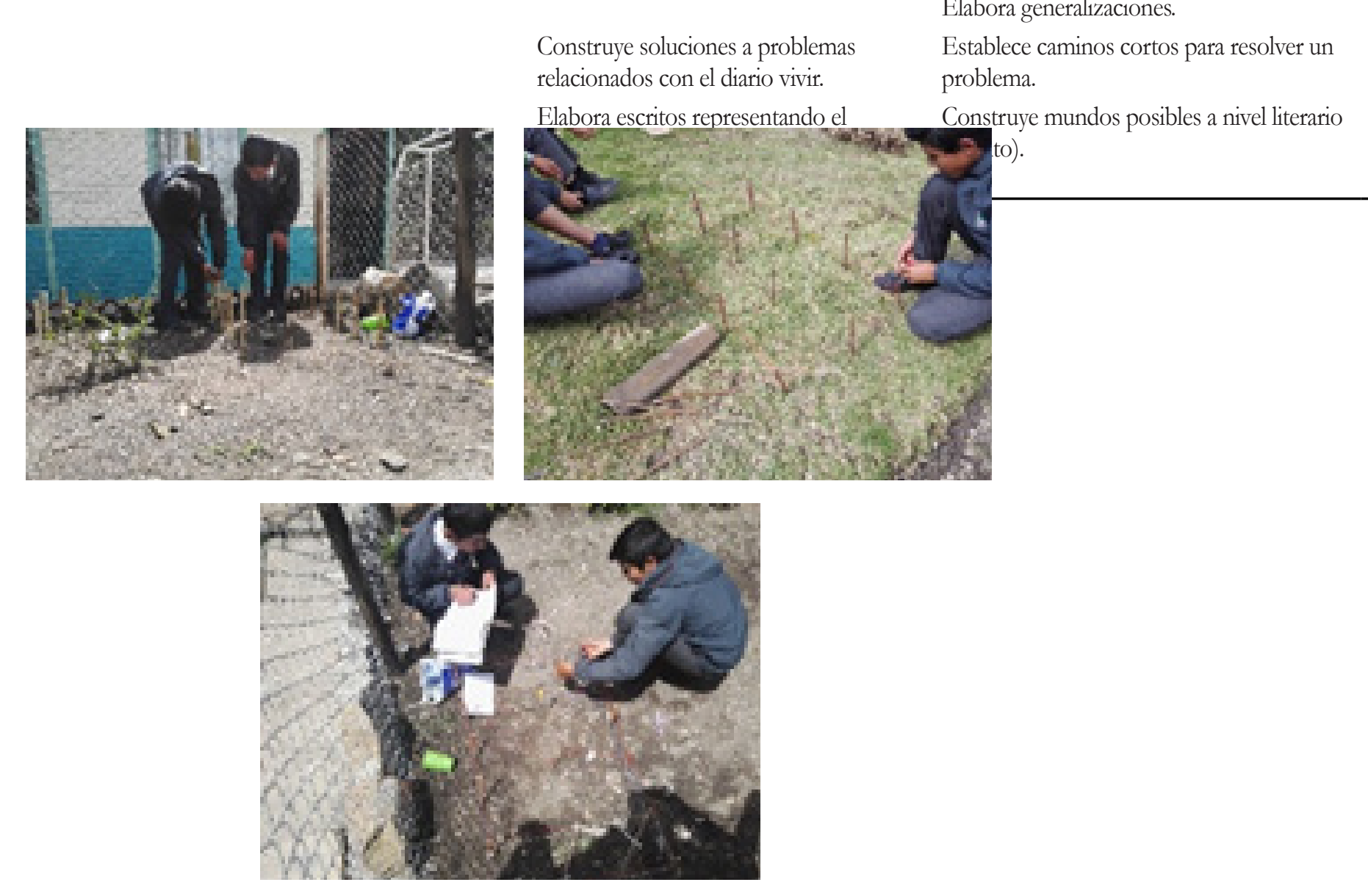

Figura 5. Práctica de loteos.

Fuente: elaboración propia.

Resuelve problemas relacionados con las realidades de contexto.

Elabora generalizaciones.

Establece caminos cortos para resolver un problema.

Sustenta conclusiones basadas en la experiencia.

Comprueba con hechos, situaciones escolares aplicadas en extraclase.

\section{Interpretativa}

Explica la influencia de la papa en la región Construye mundos posibles a nivel literario 
En Matemáticas. Se propusieron las siguientes actividades:

Realización de loteos para la siembra de papa. A los alumnos se les entregó una guía con el procedimiento, que consistía en dividir un lote de dimensiones de 1 metro por 1 metro con la condición de utilizar como mínimo ocho figuras geométricas para la siembra de la papa. Para ello, se debería realizar su encerramiento de los lotes pequeños con postes rollizos de $5 \mathrm{~cm}$ de diámetro y $30 \mathrm{~cm}$ de largo, además estos se debían unir con lana dándole tres vueltas como mínimo, que representa el alambre de púas.

Cada grupo de trabajo estaba conformado por un máximo de tres estudiantes, que en un principio se debían repartir los elementos necesarios para realizar la guía, como: lana, postes rollizos, metro y escuadras, luego escoger un lugar de la institución para realizar el loteo correspondiente. Los estudiantes debían realizar el plano del loteo propuesto en una hoja carta a escala, y determinar las áreas de los lotes y su perímetro, también debían calcular la cantidad de metros de lana que se requería para su cercado. Por último, el grupo debía exponer a sus demás compañeros el trabajo realizado, el procedimiento y cálculos obtenidos.
Como estrategia didáctica en esta actividad, se utilizó la simulación de actividades profesionales. Según Restrepo (2000), consiste en realizar en el aula de clase, actividades parecidas a las que se realizan en el entorno

profesional, en este caso en el cultivo de la papa. Los beneficios con esta actividad, fueron: aprendizaje colaborativo entre los mismos estudiantes en la formación de competencias y posibilitó el aprender a aprender mediante el abordaje de problemas en equipo.

UtilizacióndeProporcionalidad.Paraun mayor entendimiento de proporcionalidad, relaciones directas e inversas y regla de tres simple y compuesta, se realizaron talleres en los que intervenían procesos y variables utilizadas en el cultivo de papa, como: semilla, parcelas, fungicidas, hora tractor, horas hombre, sueldos y alimentación de obreros, conversión de unidades del sector agrario, entre otros. Para la apropiación del concepto de proporcionalidad, se utilizó como estrategia el aprendizaje basado en problemas, que, según Restrepo (2000), consiste en analizar y resolver problemas reales mediante el trabajo en equipo, relacionados con los contenidos del curso, teniendo en cuenta las variables utilizadas en el cultivo de papa. Para finalizar, cada estudiante junto con sus familiares debía proponer y realizar diez ejercicios de regla de tres simple y compuesta, utilizando elementos relacionados con la papa, como tiempo, ganancia, empaque, transporte, extensiones de lote y producción de papa. 
Los beneficios de estas estrategias, se evidenciaron mediante actitudes, expresiones y actividades que mostraron la pertinencia de las actividades y el empoderamiento de los estudiantes a través de lo cual se evidenció claramente la capacidad interpretativa, argumentativa y propositiva (Tobón, 2005).

Tabla 8. Categorías Competencias Básicas en Matemáticas

\begin{tabular}{|c|c|c|}
\hline Patrones de respuesta & Subcategoría & Categoría \\
\hline $\begin{array}{l}\text { Comprensión del procedimiento dado a realizar en } \\
\text { el encerramiento de diferentes lotes para el cultivo } \\
\text { de papa. }\end{array}$ & $\begin{array}{l}\text { Comprender, } \\
\text { interpretar, } \\
\text { analizar. }\end{array}$ & Interpretativa \\
\hline $\begin{array}{l}\text { Reconocer el conjunto de unidades usadas para } \\
\text { cada magnitud, longitud y área; de esta manera, } \\
\text { se podrá calcular la cantidad de alambre de púas } \\
\text { requerido para el encerramiento de los lotes y } \\
\text { para el cálculo del área que tiene cada lote para la } \\
\text { siembra de papa. }\end{array}$ & $\begin{array}{l}\text { Reconocer, } \\
\text { calcular, } \\
\text { contextualizar. }\end{array}$ & Interpretativa \\
\hline $\begin{array}{l}\text { Comprensión del mensaje planteado en } \\
\text { problemáticas que se presentan en el cultivo de } \\
\text { papa que involucran proporciones. }\end{array}$ & $\begin{array}{l}\text { Interpretación, } \\
\text { análisis, } \\
\text { contextualizar. }\end{array}$ & Interpretativa \\
\hline $\begin{array}{l}\text { Establece la información relevante para la solución } \\
\text { de un problema en el cultivo de papa que involucra } \\
\text { proporciones (regla de tres simple y compuesta). }\end{array}$ & $\begin{array}{l}\text { Extracción, } \\
\text { sintetizar, } \\
\text { contextualizar. }\end{array}$ & Interpretativa \\
\hline $\begin{array}{l}\text { Justifica a través de representaciones y } \\
\text { procedimientos, la existencia de una relación } \\
\text { de proporcionalidad directa o inversa entre dos } \\
\text { variables existente en el cultivo de papa. }\end{array}$ & $\begin{array}{l}\text { Justificar, análisis, } \\
\text { representar. }\end{array}$ & Argumentativa \\
\hline $\begin{array}{l}\text { Reconoce procesos necesarios en la resolución } \\
\text { de ecuaciones, planteadas en la solución de } \\
\text { problemáticas en el cultivo de papa. }\end{array}$ & $\begin{array}{l}\text { Reconocer, } \\
\text { calcular. }\end{array}$ & Argumentativa \\
\hline $\begin{array}{l}\text { Clasificar figuras bidimensionales de acuerdo con } \\
\text { características específicas, ya sean estas geométricas } \\
\text { o métricas. }\end{array}$ & clasificar, análisis & Argumentativa \\
\hline $\begin{array}{l}\text { Establece caminos o rutas para resolver problemas, } \\
\text { para determinar qué terreno es más favorable, con } \\
\text { el objetivo de realizar el ejercicio de determinar } \\
\text { áreas y perímetros de lotes para el cultivo de papa. }\end{array}$ & $\begin{array}{l}\text { Establecer, } \\
\text { determinar, } \\
\text { modelar. }\end{array}$ & Propositiva \\
\hline $\begin{array}{l}\text { Plantea procedimientos para resolver problemas y } \\
\text { hallar su solución, además, evalúa si esta tiene o no } \\
\text { sentido. }\end{array}$ & $\begin{array}{l}\text { Resolución, } \\
\text { modelar. }\end{array}$ & Propositiva \\
\hline $\begin{array}{l}\text { Determina medidas de atributos de figuras } \\
\text { geométricas o procedimientos, que permiten } \\
\text { calcular áreas y perímetros de lotes dispuestos para } \\
\text { el cultivo de papa. }\end{array}$ & $\begin{array}{l}\text { Determinar, } \\
\text { análisis. }\end{array}$ & Propositiva \\
\hline
\end{tabular}

Fuente: elaboración propia.

Realizando una triangulación de las categorías establecidas en las actividades de cada asignatura, se resumen los resultados obtenidos en las siguientes tablas. 
Tabla 9. Triangulación Categoría Competencia Interpretativa

\begin{tabular}{|c|c|c|c|c|}
\hline Matemáticas & Sociales & C. Naturales & Subcategoría & Categoría \\
\hline Patrones de respuesta & Patrones de respuesta & Patrones de respuesta & & \\
\hline $\begin{array}{l}\text { Comprensión del } \\
\text { procedimiento } \\
\text { dado a realizar en el } \\
\text { encerramiento de } \\
\text { diferentes lotes para el } \\
\text { cultivo de papa. }\end{array}$ & $\begin{array}{l}\text { Explican procedimientos } \\
\text { y procesos de adecuación } \\
\text { y preparación del terreno } \\
\text { para el cultivo de la papa. }\end{array}$ & $\begin{array}{l}\text { Reconoce explicaciones } \\
\text { posibles, con base en el } \\
\text { conocimiento cotidiano } \\
\text { del contexto. }\end{array}$ & \multirow{4}{*}{$\begin{array}{l}\text { Comprender, } \\
\text { interpretar, } \\
\text { analizar, } \\
\text { relacionar, } \\
\text { reconocer, } \\
\text { explicar, calcular, } \\
\text { contextualizar, } \\
\text { seguir pasos, } \\
\text { extraer, } \\
\text { sintetizar. }\end{array}$} & \multirow[t]{4}{*}{$\begin{array}{l}\text { Competencia } \\
\text { interpretativa }\end{array}$} \\
\hline $\begin{array}{l}\text { Reconocer el conjunto } \\
\text { de unidades usadas para } \\
\text { cada magnitud, longitud } \\
\text { y área; de esta manera, } \\
\text { se podrá calcular la } \\
\text { cantidad de alambre de } \\
\text { púas requerido para el } \\
\text { encerramiento de los } \\
\text { lotes y para el cálculo del } \\
\text { área que tiene cada lote } \\
\text { para la siembra de papa. }\end{array}$ & $\begin{array}{l}\text { Comprende información } \\
\text { escrita en lenguaje simple } \\
\text { relacionada con temas } \\
\text { del diario vivir. }\end{array}$ & $\begin{array}{l}\text { Identifica variables que } \\
\text { influyen en los resultados } \\
\text { de un experimento } \\
\text { empleando como fuente } \\
\text { de energía papas. }\end{array}$ & & \\
\hline $\begin{array}{l}\text { Comprensión del } \\
\text { mensaje planteado en } \\
\text { problemáticas que se } \\
\text { presentan en el cultivo } \\
\text { de papa que involucran } \\
\text { proporciones. }\end{array}$ & $\begin{array}{l}\text { Analiza algunas } \\
\text { condiciones sociales, } \\
\text { económicas, políticas y } \\
\text { culturales de la región, y } \\
\text { las plasma en un escrito } \\
\text { simple. }\end{array}$ & $\begin{array}{l}\text { Comprende la naturaleza } \\
\text { de los fenómenos } \\
\text { relacionados con } \\
\text { la electricidad y el } \\
\text { magnetismo. }\end{array}$ & & \\
\hline $\begin{array}{l}\text { Establece la información } \\
\text { relevante para la solución } \\
\text { de un problema en el } \\
\text { cultivo de papa que } \\
\text { involucra proporciones } \\
\text { (regla de tres simple y } \\
\text { compuesta) }\end{array}$ & & & & \\
\hline
\end{tabular}

Fuente: elaboración propia.

Tabla 10. Triangulación Categoría Competencia Argumentativa

\begin{tabular}{|c|c|c|c|c|}
\hline Matemáticas & Sociales & C. Naturales & Subcategoría & Categoría \\
\hline $\begin{array}{l}\text { Patrones de } \\
\text { respuesta }\end{array}$ & $\begin{array}{l}\text { Patrones de } \\
\text { respuesta }\end{array}$ & $\begin{array}{l}\text { Patrones de } \\
\text { respuesta }\end{array}$ & & \\
\hline
\end{tabular}




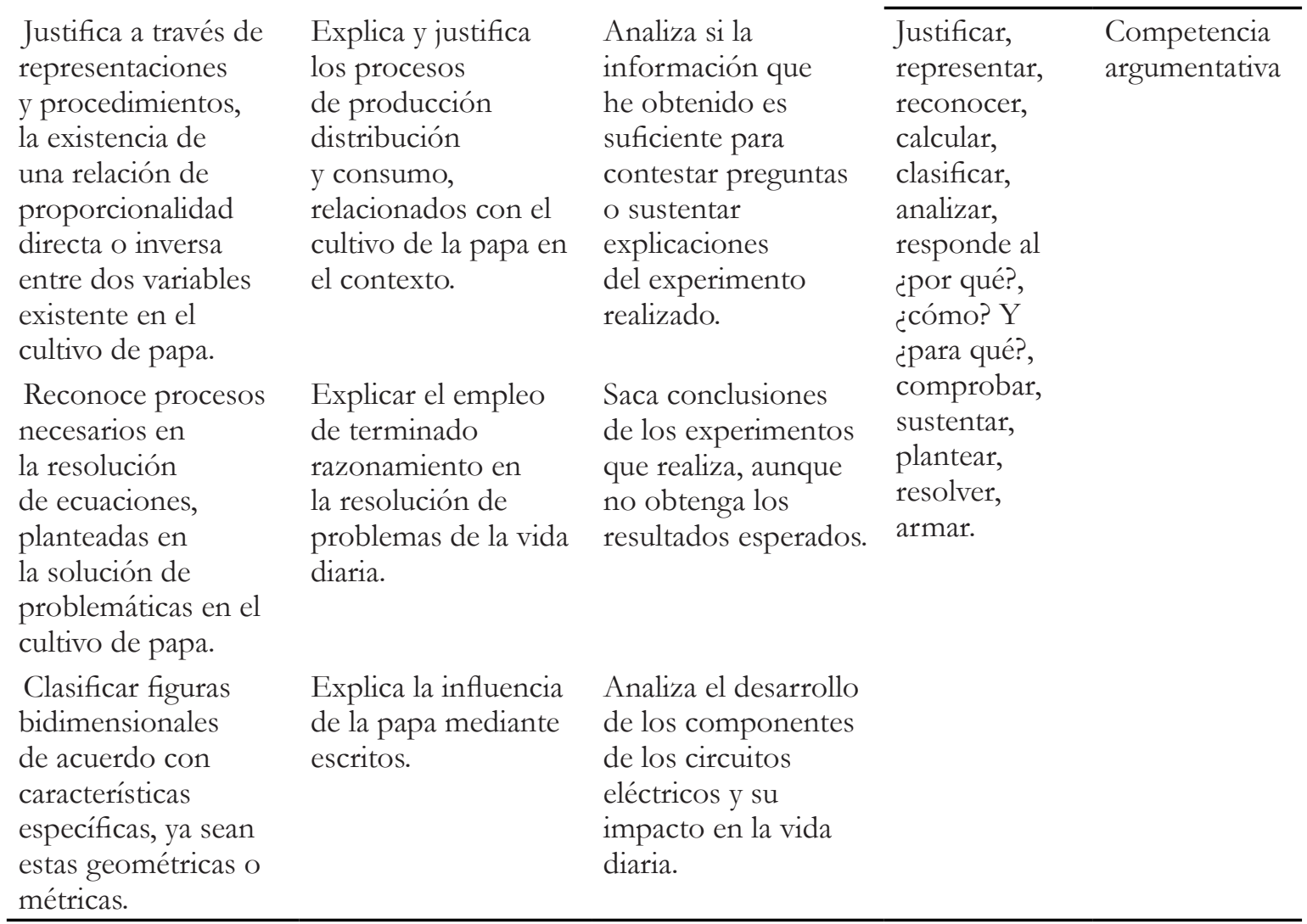

Fuente: elaboración propia. 
Tabla 11. Triangulación categoría competencia propositiva

\begin{tabular}{ccc}
\hline Matemáticas & Sociales & C. Naturales \\
\hline $\begin{array}{c}\text { Patrones de } \\
\text { respuesta }\end{array}$ & $\begin{array}{c}\text { Patrones de } \\
\text { respuesta }\end{array}$ & $\begin{array}{c}\text { Patrones de } \\
\text { respuesta }\end{array}$
\end{tabular}

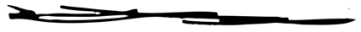

Teniendo en cuenta las tres fases de esta investigación, se mostró que existían ciertas falencias evidenciadas en el diagnóstico. Con la aplicación de la estrategia, se logró subsanar en gran parte estas deficiencias, lo que se demostró en la evaluación final. 
Categoría

Subcategoría

El uso de la estrategia

"Dispositivo Pedagógico", mostró que es posible lograr un aprendizaje más integral mediante un trabajo multidisciplinario en el sentido de que cada disciplina involucrada (matemáticas, ciencias naturales y sociales). 


\begin{tabular}{|c|c|c|c|c|}
\hline $\begin{array}{l}\text { Establece } \\
\text { caminos o rutas } \\
\text { para resolver } \\
\text { problemas, para } \\
\text { determinar } \\
\text { qué terreno es } \\
\text { más favorable } \\
\text { para realizar } \\
\text { el ejercicio de } \\
\text { determinar áreas } \\
\text { y perímetros } \\
\text { de lotes para el } \\
\text { cultivo de papa. }\end{array}$ & $\begin{array}{l}\text { Propone } \\
\text { diferentes usos } \\
\text { y aplicaciones, } \\
\text { teniendo en cuenta } \\
\text { las características } \\
\text { físicas y químicas } \\
\text { de la papa. }\end{array}$ & $\begin{array}{l}\text { Propone soluciones } \\
\text { a los problemas que } \\
\text { se presentan para el } \\
\text { funcionamiento del } \\
\text { experimento. }\end{array}$ & \multirow{4}{*}{$\begin{array}{l}\text { Establecer, } \\
\text { determinar, } \\
\text { modelar, } \\
\text { resolver, } \\
\text { analizar, } \\
\text { reconocer } \\
\text { elaborar, } \\
\text { contestar } \\
\text { adecuadamente } \\
\text { preguntas, } \\
\text { elaborar } \\
\text { generalizaciones, } \\
\text { establece } \\
\text { caminos cortos } \\
\text { para resolver } \\
\text { un problema } \\
\text { y construir } \\
\text { soluciones } \\
\text { a diversos } \\
\text { problemas. }\end{array}$} & \multirow[t]{4}{*}{$\begin{array}{l}\text { Competencia } \\
\text { propositiva }\end{array}$} \\
\hline $\begin{array}{l}\text { Plantea } \\
\text { procedimientos } \\
\text { para resolver } \\
\text { problemas y } \\
\text { hallar su solución, } \\
\text { además, evalúa } \\
\text { si esta tiene o no } \\
\text { sentido. }\end{array}$ & $\begin{array}{l}\text { Construye } \\
\text { soluciones a } \\
\text { problemas } \\
\text { relacionados con } \\
\text { el diario vivir. }\end{array}$ & $\begin{array}{l}\text { Plantea que existen } \\
\text { diversas fuentes y } \\
\text { formas de energía, } \\
\text { como limones, } \\
\text { tomates y que estas } \\
\text { se transforman } \\
\text { continuamente de } \\
\text { energía química a } \\
\text { energía eléctrica. }\end{array}$ & & \\
\hline \multirow{2}{*}{$\begin{array}{l}\text { Determina } \\
\text { medidas de } \\
\text { atributos } \\
\text { de figuras } \\
\text { geométricas o } \\
\text { procedimientos } \\
\text { que permiten } \\
\text { calcular áreas y } \\
\text { perímetros de } \\
\text { lotes dispuestos } \\
\text { para el cultivo de } \\
\text { papa. }\end{array}$} & \multirow[t]{2}{*}{$\begin{array}{l}\text { Elabora escritos } \\
\text { representando el } \\
\text { contexto rural y } \\
\text { las realidades del } \\
\text { entorno. }\end{array}$} & $\begin{array}{l}\text { Relaciono voltaje } \\
\text { y corriente con los } \\
\text { diferentes elementos } \\
\text { de un circuito eléctrico } \\
\text { elaborado con papas. }\end{array}$ & & \\
\hline & & $\begin{array}{l}\text { Formula explicaciones } \\
\text { posibles, con base } \\
\text { en el conocimiento } \\
\text { cotidiano del contexto. }\end{array}$ & & \\
\hline
\end{tabular}

Fuente: elaboración propia.

En el análisis anterior, realizado a través del proceso de categorización, se evidencia la interrelación de diferentes saberes en un contexto de ruralidad (Kayser, citado en Perico, 2011).

En estas relaciones de poderes y de saberes, se establecieron regularidades evidenciadas a través de subcategorías y categorías que mostraron el mejoramiento de las competencias básicas (Tobón, 2005). 